\title{
Analisis Sistem Penyusunan Perencanaan Obat Di Dinas Kesehatan Kabupaten Padang Pariaman
}

\author{
Syanti Rusman \\ Program Studi Magister Ilmu Kesehatan Masyarakat, Universitas Andalas \\ Email : shanti4141@gmail.com
}

Submitted : 28-01-2020, Reviewer:16-02-2020, Accepted: 20-02-2020

\begin{abstract}
ABSTRAK
Perencanaan obat adalah salah satu aspek penting dan menentukan dalam pengelolaan obat Perencanaan obat dan perbekalan kesehatan merupakan awal yang menentukan dalam pengelolaan obat. Tujuan Perencanaan Obat antara lain adalah tersusunnya rencana kebutuhan dan jadwal pengadaan secara tepat waktu untuk pelayanan kesehatan dasar.

Metode penelitian ini menggunakan pendekatan kualitatif dengan metode wawancara mendalam dan telaah dokumen yaitu untuk mendapatkan informasi yang mendalam tentang Analisis Sistem Penyusunan Perencanaan Obat Di Dinas Kesehatan Kabupaten Padang Pariaman.

Hasil dari penelitian dari komponen input menyatakan pelaksanaan penyusunan perencanaan kebutuhan obat telah mengikuti kebijakan yang sesuai dengan ketentuan dan perundangan yang berlaku, sudah dibentuknya tim perencanaan obat terpadu, SDM perencana obat yang belum pernah mengikuti bimbingan teknis perencanaan obat ,tersedianya dana untuk kegiatan penyusunan perencanan obat, sudah memadainya sarana dan prasarana penunjang kegiatan penyusunan perencanann obat, data dan informasi yang belum diolah secara benar serta jadwal penyusunan yang bersifat rutin. Dari komponen proses diketahui proses penyusunan perencanaan kebutuhan obat yang terpadu, konsultasi yang belum maksimal, bimbingan teknis yang belum kontinyu dan pelaksanaan koordinasi yang belum optimal. Komponen output menyatakan bahwa dokumen RKO yang dihasilkan telah sesuai dengan ketentuan.
\end{abstract}

Kata kunci : sistem , Perencanaan Obat, Kesehatan

\section{ABSTRACT}

Planning drug is one of the important and decisive aspect in the management of drugs. Planning drugs and medical supplies is a critical starting in the management of drug. Drug Planning Objectives include the drafting of a plan and schedule for procurement needs in a timely manner to basic health services.

Methods This study used a qualitative approach with in-depth interviews and document review is to obtain information in-depth analysis of Planning System Drugs health office Padang Pariaman regency.

The results of the research of the input component states implementation of planning needs medication has followed a policy in accordance with the rules and regulations in force, has been the establishment of teams planning of integrated medicine, human medicine planner who has never participated in the technical guidance drug plan, the availability of funds for the preparation of planning activities drugs, already inadequate facilities and infrastructure activities planning preparation of drugs, the data and information that has not been processed correctly and schedule preparation routine. Of components known process of planning process needs integrated medicine, consultation not maximum, which has not been continuous technical guidance and coordination is not optimal. Component output stating that the document $R K O$ produced in accordance with the provisions.

Key words : system, planning, drugs, health 


\section{PENDAHULUAN}

Obat merupakan komponen yang penting dalam upaya pelayanan kesehatan baik dipusat pelayanan kesehatan primer maupun ditingkat pelayanan kesehatan yang lebih tinggi. Keberadaan obat merupakan kondisi pokok yang harus terjaga ketersediaannya dan oleh sebab itu perlu perencanaan tentang penggunaan obat. Penyediaan obat sesuai dengan tujuan pembangunan kesehatan yaitu menjamin tersediannya obat dengan mutu terjamin dan tersedia merata dan teratur sehingga mudah diperoleh pada tempat dan waktu yang tepat (Depkes RI, 2005).

Kemudahan akses terhadap obat sebagai bagian dari pelayanan kesehatan bagi masyarakat merupakan hak asasi yang harus dipenuhi dan penyediaannya sebagai kewajiban bagi pemerintah. Akses masyarakat terhadap obat tidak lepas dari ketersediaannya dalam pelayanan kesehatan sehingga ketersediaan obat dalam pelayanan kesehatan merupakan bagian dari upaya peningkatan kualitas pelayanan kesehatan. Akses masyarakat terhadap obat di pengaruhi oleh empat faktor yaitu : 1) penggunaan obat rasional; 2) Harga yang terjangkau; 3) Pendanaan yang berkelanjutan; 4) sistem kesehatan serta sistem penyediaan obat yang dapat diandalkan (WHO,2000).

Proses pengelolaan obat adalah suatu proses yang urut dan merupakan suatu siklus yang tidak terpisah mulai dari perencanaan/seleksi obat, pengadaan, penyimpanan, distribusi dan tahap penggunaan (Quick et al., 1997).

Perencanaan obat dan perbekalan kesehatan merupakan awal yang menentukan dalam pengelolaan obat. Tujuan Perencanaan Obat antara lain adalah: 1) Tersusunnya rencana kebutuhan dan jadwal pengadaan secara tepat waktu untuk pelayanan kesehatan dasar; 2) Tercapainya penggunaan alokasi dana obat dan perbekalan kesehatan untuk Unit Pelayanan Kesehatan Dasar di Kabupaten/Kota secara berdaya guna dan berhasil guna; 3) Terlaksananya pengadaan obat publik dan perbekalan kesehatan untuk Unit Pelayanan Kesehatan Dasar di Kabupaten/Kota yang mendekati kebutuhan nyata; 4) Terjaminnya ketersediaan obat dan perbekalan kesehatan di Unit Pelayanan Kesehatan Dasar. Berkaitan dengan hal tersebut, diperlukan koordinasi dan keterpaduan dalam hal perencanaan kebutuhan obat dan perbekalan kesehatan sehingga pembentukan tim perencanaan obat terpadu merupakan suatu kebutuhan dalam rangka meningkatkan efisiensi dan efektivitas penggunaan dana melalui koordinasi, integrasi dan sinkronisasi antar instansi yang terkait dengan perencanaan obat di setiap kabupaten/kota (Depkes RI,2008).

Ketersediaan obat pada unit Pelayanan Kesehatan sangat mempengaruhi mutu pelayanan kesehatan. Obat perlu dikelola secara efektif dan efisien agar dapat mencapai sasaran yang diharapkan. Di era Otonomi Daerah (OTDA) dimana pembangunan kesehatan telah menjadi tanggung jawab Pemerintah Daerah (Kabupaten/Kota) dan daerah harus bisa mengatur sendiri, termasuk memenuhi kebutuhan obat. Upaya untuk memenuhi kebutuhan obat diperlukan pengelolaan dan perencanaan yang baik. Dalam hal ini selaku pelaksana teknis dan leading sektor bidang pembangunan kesehatan di daerah adalah Dinas Kesehatan Kabupaten/Kota. Dengan diberlakukannya Otonomi Daerah, setiap Kabupaten/Kota mempunyai struktur dan 
kebijakan sendiri dalam pengelolaan obat, Pengelola Obat Kabupaten/Kota disebut dengan Unit Pengelola Obat Publik dan Perbekalan Kesehatan (UPOPPK) Kabupaten /Kota (Depkes RI,1999). Dalam Kepmenkes No. 1121/Menkes/SK/XII/2008 tentang Petunjuk Teknis Pengadaan Obat Publik dan Perbekalan Kesehatan Untuk Pelayanan Kesehatan Dasar dimana tercantum bahwa perencanaan obat publik tersebut dilakukan melalui tim yang dibentuk dengan Surat keputusan Bupati/Walikota yang disebut dengan Tim Perencanaan Obat Terpadu Kabupaten/Kota. Perencanaan obat terpadu membutuhkan peran serta lintas sektor dan lintas program hingga dapat mensikronkan anggaran obat dari berbagai sumber. Keterpaduan dalam perencanaan obat sangat diperlukan agar tidak terjadi kekosongan obat ataupun duplikasi pengadaan yang berujung kepada obat berlebih, manfaat perencanaan obat terpadu : 1) Menghindari tumpang tindih penggunaan anggaran; 2) Keterpaduan dalam evaluasi, penggunaan dan perencanaan; 3) Kesamaan persepsi antara pemakai obat dan penyedia anggaran; 4) Estimasi kebutuhan obat lebih tepat; 5) Koordinasi antara penyedia anggaran dan pemakai obat; 6) Pemanfaatan dana pengadaan obat dapat lebih optimal.

\section{Di Dinas Kesehatan Kabupaten} Padang Pariaman melalui UPT Instalasi Farmasi perencanaan kebutuhan obat masih dilakukan secara manual dan sederhana karena keterbatasan sumber daya yang dimiliki sehingga sulit untuk menganalisis kebutuhan obat yang tepat, efektif dan efisien. Kesulitan timbul karena terdapat permintaan obat tertentu dari puskesmas yang tidak sesuai dengan perencanaan kebutuhan yang telah diusulkan ke Dinas
Kesehatan Kabupaten, yang terlihat dari sejumlah obat tertentu yang mengalami kekurangan dan kelebihan sehingga tergambar penggunaan anggaran kurang efektif dan efisien.

Hasil pengamatan oleh peneliti dengan cara melihat hasil pendistribusian obat publik terdapat permintaan beberapa jenis obat tertentu oleh Puskesmas ke Dinas Kesehatan Kabupaten Padang Pariaman melalui Instalasi Farmasi tidak sesuai dengan usulan yang diajukan sebelumnya. Hal ini menunjukan bahwa proses perencanaan kebutuhan obat publik di tingkat Puskesmas tidak sesuai dengan kebutuhan sebenarnya.

Masalah lain yang ditemui yaitu masih terdapat laporan data kunjungan dan pemakaian obat pasien di beberapa Puskesmas yang kurang akurat dan reliabel. Hal ini akan menyebabkan permintaan obat ke Dinas Kesehatan Kabupaten Padang Pariaman tidak sesuai dengan kebutuhan riil di Puskesmas. Dengan demikian dapat diasumsikan bahwa pemakaian obat di Puskesmas tidak sesuai dengan pelaksanaan pengobatan yang sebenarnya. Secara nyata menggambarkan perencanaan kebutuhan obat tidak tepat. Keadaan ini memerlukan upaya penelusuran dan tindak lanjut secara tepat sesuai dengan permasalahan yang ada.

\section{METODE}

Penelitian ini dilaksanakan dengan menggunakan pendekatan kualitatif dengan metode wawancara mendalam (indepth Interview) dan telaah dokumen yaitu untuk mendapatkan informasi yang mendalam tentang Analisis Sistem Penyusunan Perencanaan Obat Di Dinas Kesehatan Kabupaten Padang Pariaman. Waktu penelitian adalah mulai Juli - September 
2014. Informan penelitian ini berjumlah 15 (lima belas) Informan yang terlibat dalam proses perencanaan obat terdiri dari pengambil keputusan dari Eselon II sampai Eselon IV di Dinas Kesehatan Kabupaten Padang Pariaman yang terdiri dari Kepala Dinas, Sekretaris, Kasubbag Perencanaan, 3 (tiga) orang Kepala Bidang , 4 (empat ) orang Kepala Seksi dari masing-masing bidang yang terlibat dalam penyusunan perencanaan obat , Kepala IFK (Instalasi Farmasi Kabupaten) dan 2 (dua) orang Kepala Puskesmas yang terlibat dalam Tim Perencanaan Obat Terpadu Kabupaten (TPOTK) dan 2 (dua) orang Stakeholder dari Bappeda yang membawahi bidang kesehatan yaitu Kepala Bidang Sosial Budaya dan Kepala Seksi Pendidikan, Kesehatan, Kependudukan dan Tenaga Kerja. Data primer diperoleh dengancara wawancara yang dilakukan anatar peneliti dan informan yang dipandu dengan pedoman wawancara lau dicata/direkam. Data yang telah terkumpul dianalisis dengan metode triangulasi.

\section{HASIL DAN PEMBAHASAN}

Komponen Input :

\section{Kebijakan}

Kebijakan yang sangat mendasar dalam penyusunan perencanaan obat mengacu ke Kepmenkes No. 1121/ Menkes/SK/XII/2008 tentang Petunjuk Teknis Pengadaan Obat Publik dan Perbekalan Kesehatan untuk Pelayanan Kesehatan Dasar dimana tercantum mengenai TPOTK (Tim Perencanaan Obat Terpadu Kabupaten/Kota) - Dinas Kesehatan Kabupaten Padang Pariaman terkait penyusunan perencanaan obat sudah mengacu kepada kebijakan dan peraturan yang ditetapkan serta bersifat buttom-up planning dimana usulan perencanaan yang dimulai dari tingkat bawah/puskesmas. Kebijakan yang telah dibuat dan dilaksanakan oleh Dinas Kesehatan kabupaten Padang Pariaman antara lain dengan SK Kepala Dinas Kesehatan No. 900/142/ DINKES/2014 tentang pembentukan tim perencanaan obat terpadu kabupaten . Namun tidak secara menyeluruh karena Dinas Kesehatan Kabupaten Padang Pariaman tidak mengikutsertakan unsur dari sekretariat daerah seperti yang telah diatur dalam Kepmenkes No. 1121/ Menkes/SK/XII/2008 dan bila melibatkan unsur sekretariat daerah maka surat keputusan pembentukan tim haruslah di tandatangani oleh Bupati sehingga lebih mengikat. Dari hasil penelitian menunjukkan bahwa dalam proses penyusunan perencanaan obat di Dinas Kesehatan Kabupaten Padang Pariaman sudah dibentuk Tim Perencanaan Obat Terpadu Kabupaten (TPOTK) yang beranggotakan pejabat struktural mulai dari eselon II sampai eselon IV dan mempunyai tugas menyusun perencanaan obat . Tetapi fungsi tim ini belum berjalan secara maksimal . Tidak ada separuh dari anggota tim yang memahami tentang perencanaan obat yang tepat karena tidak pernah mengikuti pelatihan mengenai perencanaan obat, sosialisasi pun juga tidak ada.

\section{SDM}

Dalam pelaksanaan penyusunan perencanaan obat, kasie/ pemegang program dibantu oleh staf. Dan apabila dilihat dari latar belakang pendidikannya masih ada yang berlatar belakang Diploma dan non kesehatan. Dikhawatirkan usulan perencanaan obat menjadi kurang sempurna karena SDM yang berlatar belakang non kesehatan bukan keahliannya dalam 
merumuskan kebutuhan dibidang kesehatan.

\section{Anggaran}

Di Dinas Kesehatan Kabupaten Padang Pariaman ditemukan bahwa dalam penyusunan perencanaan obat telah dianggarkan sejumlah dana guna menunjang kelancaran proses kegiatan penyusunan perencanaan obat . Anggaran ini termasuk kedalam Program Pengadaan Obat dan Perbekalan Kesehatan . Kegiatan yang masuk dalam program ini adalah rangkaian penyusunan perencanaan obat serta pengadaan obat dan perbekalan kesehatan untuk seluruh puskesmas di wilayah kerja Kabupaten Padang Pariaman dengan indikator keluaran adalah tersedianya dokumen Rencana Kebutuhan Obat ( RKO) dan indikator hasilnya adalah terlaksananya pengadaan obat dan Perbekalan Kesehatan .

\section{Sarana dan Prasarana}

Sarana dan prasarana seperti sarana komputer dan penunjang lainnya sudah memadai dan bukan merupakan hambatan dalam penyusunan perencanaan di Dinas Kesehatan Kabupaten Padang Pariaman, akan tetapi pemeliharaan terhadap sarana ini masih kurang karena ditemukan ada beberapa komputer yang tidak berfungsi. Ini disebabkan karena belum adanya SDM khusus yang bertugas dalam perawatan sarana seperti komputer mi. Disamping itu sebagian SDM lebih tertarik untuk memanfaatkan sarana laptop pribadi dalam menunjang pekerjaannya sehingga perhatian terhadap sarana kantor agak terabaikan .

Fasilitas transportasi maupun alat komunikasi yang mendukung proses penyusunan perencanaan obat juga tersedia walaupun tidak ada sarana khusus untuk penyusunan perencanaan obat, namun masih bisa memanfaatkan sarana yang ada. Dan saat ini komunikasi semakin dipermudah dengan adanya e-mail serta telepon selular (handphone).

\section{SIM/ Data dan Informasi}

Di Dinas Kesehatan Kabupaten Padang Pariaman ditemukan bahwa sumber data yang dipergunakan dalam penyusunan perencanaan berasal dari laporan puskesmas yaitu LPLPO serta laporan SP2TP. Selain itu sumber data lain yang dipakai adalah data hasil olahan IFK. Akan tetapi data yang terkumpul saat ini masih kurang lengkap dan sumber data yang dimiliki belum terjamin kevalidannya terkait dengan SDM pengumpul maupun pengolah data.Kurang lengkapnya data disebabkan karena masih ada dan beberapa puskesmas yang sering telat menyerahkan laporan bulanan, triwulan maupun laporan tahunannya. Tetapi hal ini tidak terlalu jadi masalah oleh SDM pengelola data obat di IFK karena dengan data yang ada saat ini dianggap cukup mewakili untuk melakukan analisis situasi dalam penentuan kebutuhan obat yang akan datang dengan asumsi bahwa kebutuhan yang akan datang tidak akan jauh berbeda dengan pola pemakaian tahun tahun sebelumnya. Padahal apabila diperhatikan pola maupun kecenderungan masalah kesehatan tidak sama ditiap wilayah. Apalagi wilayah Kabupaten Padang Pariaman yang terdiri dari wilayah pesisir dan wilayah perbukitan, tren penyakit diwilayah ini jelas berbeda.

Komponen Proses

\section{Alur Proses Penyusunan}

Dari SDM pengelola data diluar IFK sebagai UPT pengelola obat di Dinas Kesehatan Padang Pariaman masih ada SDM pengolah data program yang bukan ahli dibidangnya. Hal ini menyebabkan data 
mengalami proses yang cukup panjang hingga akhirnya menjadi sebuah informasi.Dalam penyusunan perencanaan obat di Dinas Kesehatan Kabupaten Padang Pariaman belum ada jadwal khusus hanya berdasarkan kegiatan rutin setiap tahun. Dan proses penyusunan berdasarkan jadwal yang ada sudah dimulai semenjak awal tahun untuk perencanaan kebutuhan tahun berikutnya.

bahwa perencanaan obat telah dilaksanakan secara bottom $U p$, dimana prosesnya dimulai dari puskesmas. Perencanaan obat di puskesmas dilakukan oleh pengelola obat puskesmas. Metode yang digunakan adalah metode konsumsi, tidak ada tim perencanaan obat untuk tingkat puskesmas. Pengelola obat menggunakan LPLPO sebagai sumber data dasar perencanaan obat. LPLPO memberikan informasi penggunaan rata-rata obat perbulan di puskesmas. Rekap LPLPO menjadi acuan untuk perencanaan obat puskesmas yang kemudian di ajukan ke Dinas Kesehatan melalui IFK.

2. Konsultasi

Terkait konsultasi ditemukan bahwa pelaksanaan konsultasi sehubungan dengan perencanaan obat dilakukan ke Dinas Kesehatan Propinsi . Dalam upaya untuk sinkronisasi program dan kegiatan dengan propinsi . Konsultasi tersebut dilakukan langsung oleh pemegang program sehingga dalam menyusun perencanaan nantinya para pemegang program sudah mengetahui program dan kegiatan yang didanai propinsi dan tidak menganggarkan lagi program dan kegiatan tersebut dalam anggaran APBD. Tetapi dalam pelaksanaannya, monitoring terhadap pelaksanaan konsultasi masih kurang maksimal. Sehingga berakibat pada kurang terakomodirnya usulan rencana dari propinsi dalam Renja Dinas Kesehatan Kabupaten Padang Pariaman. Padahal program-program yang didanai oleh propinsi juga mempunyai potensi yang cukup besar dalam pencapaian target indikator kesehatan di Kabupaten Padang Pariaman.

\section{Bimbingan Teknis}

Bimbingan teknis dalam hal penyusunan perencanaan obat tidak ada dilakukan oleh Dinas Kesehatan Kabupaten Padang Pariaman. Pemda melalui Bappeda hanya melakukan bimbingan teknis untuk perencanaan secara umum. Bimbingan teknis yang diberikan menurut informan dari Bappeda adalah apabila ada kebijakan baru atau adanya perubahan dalam sistem perencanaan maka dilakukan bimbingan teknis dan arahan terkait dengan perencanaan. Sedangkan bimbingan teknis mengenai perencanaan obat dilakukan oleh Dinas Kesehatan propinsi dan hanya untuk tenaga kefarmasian yang mengelola obat namun juga tidak setiap tahun diadakan.

\section{Koordinasi}

Koordinasi lintas program di Dinas Kesehatan Kabupaten Padang Pariaman masih belum optimal pelaksanaannya karena dalam menentukan program belum dibahas secara bersama-sama. Sehingga nantinya dari masing- masing bidang menghasilkan usulan program maupun kegiatan prioritas yang banyak, padahal indikator yang ingin dicapai sama.Kurang optimalnya pelaksanaan koordinasi disebabkan pemahaman yang kurang akan koordinasi. Makna koordinasi yang dilakukan selama ini hanya dalam konteks pelaksanaan kegiatan, padahal dalam merencanakan juga diharapkan ada koordinasi sehingga apabila ada kesamaan maksud dan tujuan yang ingin dicapai dapat direncanakan bersama 
sehingga dapat menghemat dari segi tenaga, biaya dan waktu.

\section{Komponen Output}

Dokumen perencanaan obat yang dihasilkan adalah Rencana Kebutuhan Obat (RKO) yang berasal dari usulan program dan data dari IFK . RKO Dinas Kesehatan Kabupaten Padang Pariaman berupaya mengacu pada kebutuhan dalam pelayanan kesehatan dasar. RKO ini berpatokan kepada pagu anggaran yang ditetapkan untuk dinas kesehatan. RKO ini bukan acuan dalam penyusunan RKA,RKO ini pun tidak terdapat dalam DPA Dinas Kesehatan Kabupaten Padang Pariaman.

\section{KESIMPULAN}

Penyusunan perencanaan obat dilaksanakan dengan berpedoman kepada kebijakan yang telah ditetapkan oleh pemerintah pusat maupun kebijakan pemerintah daerah. Perencanan obat disusun berdasarkan data tahun sebelumnya serta disesuaikan dengan ketersediaan anggaran

Sudah dibentuknya tim perencanaan obat terpadu namun tim ini belum berperan secara maksimal serta SDM perencana masih ada dari non kesehatan dan masih ada yang belum pernah mengikuti pelatihan tentang perencanaan obat. Penyusunan perencanaan obat di Dinas Kesehatan Kabupaten Padang Pariaman sudah dianggarkan dana yang dialokasikan dalam anggaran APBD yang dimasukkan dalam Program Pengadaan Obat dan Perbekalan Kesehatan yang besarannya sesuai dengan kebutuhan dan masih dalam batas kewajaran.

Sarana dan prasarana yang mendukung penyusunan perencanaan obat di Dinas Kesehatan Kabupaten Padang Pariaman sudah cukup memadai, namun pemeliharaan sarana dan prasarana masih kurang maksimal.

Data dari puskesmas yang digunakan dalam penyusunan perencanaan sering rlambat dilaporkan serta masih diragukan kevalidan data tersebut terkait SDM pengumpul maupun pengolah data bukan orang yang ahli dibidangnya.

Penyusunan perencanaan obat di Dinas Kesehatan Kabupaten Padang Pariaman belum ada jadwal yang ditentukan, hanya berdasarkan kegiatan rutin saja.

Alur proses penyusunan perencanaan obat di Dinas Kesehatan Kabupaten Padang

ariaman sudah mengikuti alur ataupun langkah-langkah perencanaan terpadu, penyusunan perencanaan obat menggunakan data emakaian jumlah obat tahun sebelumnya ( metode konsumsi).

Konsultasi dalam penyusunan perencanaan obat dilakukan ke Dinas Kesehatan Propinsi dan rencana terkait program yang didanai dengan dana program dari propinsi dilakukan langsung oleh pemegang program tetapi monitoring terhadap pelaksanaan dan hasil konsultasi masih kurang maksimal

Bimbingan teknis terkait penyusunan perencanaan obat di laksanakan oleh Dinas Kesehatan Propinsi dan hanya untuk tenaga kefarmasian namun tidak setiap tahun diadakan Bappeda hanya melaksanakan bimbingan teknis dan arahan apabila ada perubahan sistem dalam Koordinasi lintas program sudah berjalan tetapi dalam pelaksanaannya masih belum optimal, sedangkan koordinasi lintas sektor belum tergambar.

Dokumen yang dihasilkan adalah Rencana Kebutuhan Obat (RKO) Dinas Kesehatan Kabupaten Padang Pariaman yang ditandatangani oleh Kepala Dinas Kesehatan Kabupaten Padang Pariaman. 


\section{SARAN}

1. Mengikuti pelatihan manajemen obat pada tenaga farmasi yang mengelola obat di dinas kesehatan dan puskesmas secara berkala dan berkesinambungan sehingga memahami tentang pengelolaan obat yang baik dan metode perencanaan kebutuhan obat yang sesuai dengan pedoman yang telah ditetapkan oleh Kementerian Kesehatan.

2. Data yang digunakan untuk penyusunan perencanaan obat haruslah data yang sudah di uji kevalidannya melalui pengolahan data agar lebih akurat, efektif dan efisien bukan data yang dikumpulkan secara manual.

3. Melibatkan kembali unsur Sekretariat Daerah dalam tim perencanaan obat terpadu dengan SK Tim yang ditandatangai oleh Bupati sehingga lebih mengikat.

\section{Daftar Pustaka}

Amiruddin, 2007. New Paradigm For Public Health.Bagian II:Siklus PerencanaanKesehatan. http://ridwanamiruddin.wordpress.co m/2007/05/05/konsep-baru-

paradigma-kesehatan-bab-2-siklusperencanaan/

Basri H, Mubasysyir, 2002. Pendekatan Sistem Dalam Perencanaan Program Kesehatan. Jurnal Manajemen Kesehatan,Vol.10/N0.02/ Juni 2007. Pusat Manajemen Pelayanaan Kesehatan Fakultas Kedokteran Universitas Gajah Mada, Yogyakarta.

Basrowi,S, 2002. Metode Penelitian Kualitatif Prespektif Mikro. Insan Cendiaka, Surabaya .
Badan Pusat Statistik, 2013. Padang Pariaman Dalam Angka Tahun 2013. Padang Pariaman.

Departemen Kesehatan Republik Indonesia, 2000. Indonesia Sehat 2010. Kesepakatan Pertemuan Nasional Bupati dan Walikota se Indonesia Dalam Rangka Desentralisasi di Bidang Kesehatan. Departemen Kesehatan Republik Indonesia, Jakarta.

Departemen Kesehatan Republik Indonesia, 2002. Pedoman Pengelolaan Obat Publik dan Perbekalan Kesehatan. Departemen Kesehatan Republik Indonesia, Jakarta.

Departemen Kesehatan Republik Indonesia, 2005. Rancangan Kebijakan Obat Nasional. Departemen Kesehatan Republik Indonesia, Jakarta.

Departemen Kesehatan Republik Indonesia, 2006. Kebijakan Obat Nasional. Departemen Kesehatan Republik Indonesia, Jakarta.

Departemen Kesehatan Republik Indonesia, 2009. Pedoman Pengadaan Obat Publik pada Pelayanan Kesehatan Dasar. Departemen Kesehatan Republik Indonesia, Jakarta.

Departemen Kesehatan Republik Indonesia, 2009. Rencana Strategis

Kementerian Kesehatan Tahun 2009

- 2014. Departemen Kesehatan Republik Indonesia, Jakarta.

Departemen Kesehatan Republik Indonesia, 2009. Sistem Kesehatan Nasional. Departemen Kesehatan Republik Indonesia, Jakarta.

Dinas Kesehatan Padang Pariaman, 2012. Dokumen LAKIP ( Laporan Akuntabilitas Kinerja Instansi Pemerintah ) Tahun 2012. 
Dinas Kesehatan Padang Pariaman, 2010. Rencana Strategis Dinas Kesehatan Kabupaten Padang Pariaman Tahun 2010 - 2015.

Dinas Kesehatan Padang Pariaman, 2012. LPPD Dinas Kesehatan Kabupaten Padang Pariaman Periode 2011 S/D 2012

Dwiyanto A, 2003. Reformasi Tata Pemerintahan dan Otonomi Daerah. PSKK- UGM, Yoyakarta

Egan S, 1993. Adding Value : A Systematic

Guide to Business Driven Management and Leadership. Jossey-Bass Publishers, San Fransisco.

Ernawati C.T, 2004. Analisis Sistem Perencanaan Dan Penganggaran Kesehatan Di Dinas Kesehatan Kota Payakumbuh Provinsi Sumatera Barat Tahun 2004.Tesis Universitas Indonesia, Jakarta.

FKM-UI, 2008. Gizi dan Kesehatan Masyarakat, Departemen Gizi dan Kesehatan Masyarakat, Edisi Revisi. Rajawali Pers, Jakarta

Gani A, 2001. Bahan Advokasi Kesehatan: Kesehatan dan Pembangunan Daerah Kota Yogyakarta. Jakarta.

Hamid E.S, 2004. Memperkokoh otonomi Daerah ( Kebijakan, Evaluasi dan Saran ). UII Press, Yogyakarta.

Imron M, 2009. Metodologi Penelitian Bidang Kesehatan. Sagung Seto, Jakarta.

Muninjaya A.A.G, 2004. Manajemen Kesehatan, Edisi 2. EGC, Bandung.

Notoatmojo S, 2007. Ilmu Kesehatan Masyarakat : Prinsip - Prinsip Dasar, Cetakan Kedua. Rineka Cipta, Jakarta.

Pemerintah Daerah Kabupaten Padang Pariaman, 2012. Peraturan Bupati
Padang Pariaman tentang Uraian Tugas, Padang Pariaman.

Quick,J.D, et al, 1997. Managing Drug Supply,The Selection,Procurement, Distribution And Use Of Pharceutical. Kumarin Press Inc, Hardford .

Rondinelli D.A, Chema, 1983. Decentralization in Developing Countries. World Bank, Washington DC.

Rosidin, Utang, 2010. Otonomi Daerah Dan Desentralisasi. Pustaka Setia, Bandung.

Sabardi A, 2001. Manajemen Pengantar. Edisi Revisi. Unit Penerbit Dan Percetakan Akademi Manajemen Perusahaan Ykpn, Yogyakarta.

Santoso B, 2000. Kajian Sistem Logistik

Obat : Berbagai Pertimbangan Dalam Reformasi Kebijakan. Medika, Yogyakarta

Sarwono, Jonathan, 2006. Metode Penelitian Kuantitatif Dan Kualitatif, Cetakan Pertama. Graha Ilmu, Yogyakarta.

Sugiwono, 2001. Metodelogi Penelitian Bisnis, Cetakan ketiga. Alfabeta, Bandung. Syafrawati, 2002. Analisis Perencanaan Tahunan Kesehatan Sub Dinas Pencegahan Dan Pemberantasan Penyakit Dians Kesehatan Kota Depok Tahun 2002. Jurnal Kesehaatan Masyarakat,Vol 01/ No. 01/ September 2006. Program Studi Ilmu Kesehatan Masyarakat Fakultas Kedokteran Universitas Andalas, Padang.

Symond, Denas, 2006. Pengembangan Model Perencanaan dan Penganganggaran Kesehatan Tahunan di Dinas Kesehatan Kota 
Padang Tahun 2006. Jurnal Kesehatan Masyarakat,Vol 02/ No. 01/September 2007. Program Studi Ilmu Kesehatan Masyarakat Fakultas Kedokteran Universitas Andalas, Padang.

Trisnantoro, L, 2001. Perubahan Sistem Kesehatan Wilayah Akibat Kebijakan Desentralisasi. Jurnal Manajemen Pelayanan Kesehatan, No. $\quad 2001$.

UGM, Yogyakarta.

Undang-Undang Kesehatan Nomor 36 tahun 2009

Velasquez,G, 1998. Health Reform and Drug Financig.WHO.

Wursanto, 2005. Dasar - Dasar Ilmu Organisasi. Andi Pres, Yogyakarta.

Yunita, 2010. Analisis Sistem Penyusunan Perencanaan Tahunan Dinas Kesehatan Kabupaten Padang Pariaman Tahun 2010.Tesis. Universitas Andalas, Padang.

Kabupaten Bengkulu selatan Tahun 2013.

Tesis Program Pasca Sarjana Universitas Diponegoro . 